a Radiation Therapy Oncology Group-Medical Research Council co-operative randomised study. Int $\mathcal{f}$ Radiat Oncol Biol Phys 1988;15:1085-90.

4 Russell KJ, Laramore GE, Krall JM, et al. Eight years' experience of neutron radiotherapy in the treatment of stages $C$ and ence of neutron radiotherapy in the treatment of stages $C$ an D prostate cancer: updated results for the Radiation Therapy Oncology Group 7704 randomised clinical trial. Prostate 1987 ,
11:183-93. 5 Schmitt G, Schnabel K, Sauerwein W, Schere TE. Neutron and neutron-boost irradiation of soft tissue sarcomas. A 4.5 year analysis of 139 patients. Radiother Oncol 1983;1:23-9.

6 Cohen L. Normal tissue reactions and complications following high energy neutron beam therapy. 1. Crude response rates. Int Y Radiat Oncol Biol Phys 1989;16:73-8.

SIR, - The rationale for the clinical evaluation of high linear energy transfer neutral particle beam radiation therapy (fast neutrons) in radiation treatment of patients with cancer is based on the expected clinical gains because of the radiobiological characteristics of such high linear energy transfer beams. Fast neutrons are both neutral and high linear energy transfer beams, and their radiobiological characteristics offer great potential for improving local regional control in many tumour sites.

Dr R S Stone in 1947 related the clinical experience of using neutron beams at the University of California Medical School in San Francisco from 1938 to 1943 . The technique was abandoned largely because the late effects were proportionally greater than the early effects than would have been expected from previous experience with $x$ rays.

It was Sheline's review in the 1960 s that catalysed a resurgence of interest in clinically assessing fast neutrons. Dr Mary Catterall using a cyclotron at the Hammersmith Hospital showed substantial clinical improvement in local regional control in tumours of the head and neck, particularly those of salivary glands. These results were achieved in spite of a primitive machine with a low energy beam, but they were noticeably better than could have been expected from other treatment regimens with $x$ rays. Dr Catterall was judicious in selecting her comparisons for the neutron treated patients. Neutrons are at least as good as megavoltage photons in treating squamous cell carcinomas of the head and neck. The conclusions from the Hammersmith trials were comparable with those obtained in terms of local control and incidence of complications from clinical trials in the United States, where inadequate and inappropriate cyclotrons (non-hospital based physics research machines) were also used to develop neutrons. In all these trials radiation oncologists were exploring new treatment techniques without precise basic radiobiological data. Salivary gland tumours and possibly carcinomas of the prostate are better treated with neutrons. Improvements have also been shown at other sites but not at an acceptable level of significance. All of these results were obtained with cyclotrons that had inferior clinical performance characteristics.

Once the validity of the fast neutron beam for treating cancer was identified the technical demands of machinery and our expectations of treatment were more realistic than at the outset.

It was against this background that the National Cancer Institute in the early 1970s identified the clinical assessment of fast neutron beams as a high priority in cancer research in the United States. Research programmes are underway primarily at the University of Washington, Seattle, the University of California at Los Angeles, the M D Anderson Hospital, Houston, the Fermi Laboratory in Batavia, Illinois, and the Cleveland Clinic. The present clinical trials were based on a more precise knowledge of tumour biology and observations in radiation biology supporting the rationale for neutron therapy. Neutrons would be more appropriate for tumours in which the proportion of hypoxic tumour clonogens is high or reoxygenation does not occur in a regularised way. Also neutrons would be better when clonogens are characterised by a broad shoulder in their $x$ ray dose survival curve. Probably tumours that are highly proliferative may be better treated with neutrons because they do not show self sensitisation by cell cycle redistribution and possibly also because non-proliferative cells repair more injury induced by $x$ rays than proliferative cells, leading to higher relative biological effectiveness at lower doses of neutrons. It has been estimated that 10 to $20 \%$ of all malignant tumours may be better treated with neutrons, based on the clinical experience accrued thus far.

The Hammersmith initiative and the limited experience in the United States have constituted the basic foundation on which clinical trials in many centres world wide have been developed These initiatives led to a more precise definition of the criteria by which patients would be selected for treatment and of the need for high energy fas neutrons, a better understanding of basic biology, and a consolidation of experience within a few institutions with hospital based machines.

The addition of the high energy cyclotron at St Thomas's Hospital will add immeasurably to the basic clinical effort in fast neutron assessment. The conflicting appraisals even more than the conflicting results of past neutron trials must not be allowed to compromise the potential for well controlled, well designed clinical trials. The pessimism expressed by the critics is far out of proportion to the relevance of the need to pursue appropriate clinical assessment. Unfortunately the doom, gloom, and irrelevant criticism of the new cyclotron facility at St Thomas's may result in further delay in the installation of an important research facility for assessing fast neutron treatment.

LUTHER W BRADY

Department of Radiation Oncology and Nuclear Medicine.

Hahnemann University,

Philadelphia,

Pennsylvania

United States

Department of Radiation Oncology,

WILLIAM E POWERS

Wayne State University

Detroit,

Michigan,

United States

SIR, - The polarisation of radiation oncologists in the United Kingdom on the subject of neutron therapy ${ }^{1.3}$ is fascinating to follow for radiotherapists in distant lands. All medical, surgical, and radiation treatment of cancer can be likened to walking a plank with, on one side, tumour recur rence and, on the other, normal tissue damage. Fast neutron treatment, so far, seems to be more like walking a very thin wire. Whether the introduction of high energy neutrons will broaden the wire to plank size or merely secrete the late damage beneath the surface, as Dr Peter Blake suggests, ${ }^{+}$is the crux of the matter. Obviously the answers will come from properly conducted trials at Clatterbridge, and the question is really whether the United Kingdom wants and can afford to speed up this process by setting up a second cyclotron for medical irradiation.

Presumably the authorities have done the sums and are prepared to divert funds from something else (there never seems to be spare money) to perform this experiment. I wonder if they have considered whether the proposed treatment is likely to supplant conventional radiation treatmen in a large proportion of patients with cancer. If so there may be well based demands that the budge for linear accelerator replacements be expanded beyond the dreams (nightmares) of NHS planners. It might be more in their interests to let the answers appear slowly.

From the Second World viewpoint of Australia the argument that the British government is too generous with its provision of facilities is particularly galling. Our masters have become adept at passing the buck between federal and state responsibilities for adequate radiation therapy to cover the needs of our populations. Several inquiries in New South Wales have recommended amalgamating small departments without much success. Committee reports, followed by feasibility studies and then working parties, have managed to postpone for 20 years any action on expanding facilities in Victoria in a properly planned manner. The author of a comprehensive study showing that Australia refers $36 \%$ of patients with cancer for assessment and treatment in radiation therapy, in contrast to the rest of the civilised world, where up to $55 \%$ of patients are treated, 'has been ignored in the formation of a working party to make recommendations to a subcommittee of the Conference of Health Ministers, who are unlikely to come to any conclusion involving a practical solution. There are some advantages in working in a unified bureaucracy.

Peter MacCallum Cancer Institute

T F SANDEMAN Melbourne, Victoria 3000

Australia

1 Smith R. Radiotherapy's second setback. Br Med f 1988;297: 1625-6. (24-31 December.)

2 Lambert J, Goolden A, Munro A, Rodger A, MacDougall H. Radiotherapy's second setback. Br Med f 1989;298:183. (21 January.

Catterall M. Radiotherapy's second setback. Br Med J 1989;298: 384. (11 February.)

4 Blake P. Radiotherapy's second setback. Br.Med f 1989;298:384. (11 February.)

Wigg DR. Radiation oncology in Australia: an increasing crisis. Australas Radiol 1988;32:24-37.

\section{Control of hospital infection}

SIR, - Professor Mark Casewell raised a few topical but pertinent questions regarding control of infection in the hospital as well as in the community. How should the current hospital control of infection officers, of whom four fifths are consultant medical microbiologists, respond and relate to the director of public health district control of infection officer axis as proposed in the Acheson report $^{2}$ for controlling infection in a district? Professor Casewell also highighted the problem of singlehanded microbiologists in a district general hospital providing 24 hour cover and doubted the feasibility of microbiologists undertaking the additional responsibility of control of infection in the community. Smith has questioned the concept of managerial accountability that has been advocated in both the Cooke ${ }^{3}$ and the Acheson reports. ${ }^{+}$

All these issues have direct relevance to me and many others in Britain who are singlehanded medical microbiologists as well as control of infection officers in district general hospitals. For 14 years I have provided service without any junior medical support for 24 hours a day and seven days a week except when away on leave. Since 1987 after protracted representation I have been provided with alternate weekend medical cover and a control of infection nurse. Why did I put up with such an onerous commitment? I had no other alternative but to carry on because of my professional responsibility; it was not for the stick or the carrot. I have been carrying out my duties, like most of my consultant colleagues, without having a managerial accountability. I find it difficult to separate managerial duties from my clinical responsibilities and control of infection and laboratory work, and I wish somebody could spell out the managerial duties which do not affect my other functions. What most of us wanted were adequate resources, staff, medical cover, and management support but not this simplistic managerial accountability. Unless necessary resources are available medical microbiologists should think twice before accepting the responsibility of control of infection, in whatever capacity. 